\title{
Comparison of Lead Absorption Ability of Bougainvillea (Bougainvillea Spectabilis L.) Leaves in Two Cities in Metro Manila, Philippines
}

\author{
Karen Ann Marie M. Dela Cruz, Sandra Dawn G. Burgos, Mac Ardy J. Gloria, \\ Khristie Michelle D. Ventura, and Judilyn Solidum
}

\begin{abstract}
Heavy metals, such as lead, have caused deleterious effect not only to the environment, but also to the public's health. In the Philippines, the ornamental plant Bougainvillea has been planted on the main roads of cities due to its capacity to thrive in heavily polluted areas. Studies show that Bougainvillea may be utilized to reduce heavy metal pollution through absorption and adsorption in soil and air, respectively. In this study, the plant's leaves were used to measure the lead accumulated, adsorbed and absorbed from two cities in Metro Manila, specifically Las Piñas and Manila. The lead concentration of the plant and its soil was measured through Flameless Atomic Absorption Spectrophotometer (AA-6300, Shimadzu, France), and the duration of measurement lasted for nine months with four time periods $(0,3$ 6 and $9^{\text {th }}$ month-interval). Two-way t-test and ANOVA were used to analyze the data gathered. It was found that there is no sufficient evidence to conclude that lead content of the plants in Manila differs significantly from that of Las Piñas. Moreover, results show that Bougainvillea lead uptake may vary depending on various environmental factors, such as concentration of lead in soil, climatic condition, degree of heavy metal pollution and complexes of lead form in other soil components.
\end{abstract}

Index Terms-Bougainvillea, flameless atomic absorption spectroscopy, heavy metals, lead absorption ability.

\section{INTRODUCTION}

Heavy metals are present as pollutants in the air which may cause harm to the public. According to the World Health Organization (WHO) heavy metals such as lead in air of Manila are greatly exceeding the established safety limits, and concentrations of suspended particulate matter are dangerously high. With this fact, air pollution in the country has been a problem which requires attention, monitoring and long term solutions. Majority of the sources of air pollution come from automobiles, gases from burning of coal and fossil fuels, as well as smelting of iron and non-ferrous metals [1].

Lead in particular has been the heavy metal of interest in most of the studies because of its deleterious effect not only in the environment but also to public's health as it accumulates through time [1]. Moreover, lead is one of the most common contaminants in urban soil that can be taken up by the plants. Majority of lead in the environment come from

Manuscript received December 5, 2012; revised February 15, 2013. This work was supported in part by the Saliksikan para sa Kalilkasan and the University of the Philippines College of Pharmacy.

Karen Ann Marie M. Dela Cruz is with UP Saliksikan para sa Kalikasan (SALIKASAN), Philippines (e-mail: karenannster@gmail.com). air borne emission and deterioration of lead based paint. Lead from the soil can be uptake by the plant through its root or leaves. According to the study conducted by Yan-Ju and Hui in 2008 [2], plants provide enormous leaf area for impringement, absorption and accumulation of air pollutants to reduce their levels in the environment including air borne lead. The ability of plant to absorbed lead from two sources soil and air has a great environmental significance in phytoremediation of heavy metals [1].

In the Philippines, bougainvillea has been recommended by the Metropolitan Manila Development Authority to be used as ornamental plant in the main roads of the city due to its capacity to thrive in heavily polluted area such as urbanized city. Although it has not been used as bioindicator, it has been determined that this plant accumulates heavy metals such as Nickel [3] and may be utilized as one of the plants used to reduced heavy metal pollution from the environment.

In this study, bougainvillea leaves were used to measure the lead accumulated, adsorbed and absorbed from two cities in Metro Manila, specifically Las Piñas and Ermita Manila. Las Piñas is known as one of the cleanest cities in Metro Manila belonging in the list of "Clean and Green Hall of Fame" awarded by the Philippine government. It is also the first local government unit in the Philippines that has received the prestigious Global 500 roll of Honour of the United Nations Environment Programme. Manila on the other hand is the capital of the Philippines. The district of Ermita in Taft Manila was reported to be the most air polluted district in Manila [4]. The main objective of this study was to determine and compare the ability of Bougainvillea spectabilis L. (Fam. Nyctaginaceae) leaves to absorb, adsorb and accumulate lead situated in the two cities. The specific objectives of this study are to determine the ability of bougainvillea to absorbed and adsorbed airborne and soil borne lead determined at $0,3,6,9$-month period by Flameless Atomic Absorption Spectroscopy and to determine if there is a significant difference in the accumulation and absorption of lead among the bougainvillea plants in the two cities.

\section{Methodology}

\section{A. Procurement and Planting of Bougainvillea \\ 1) Materials}

Plant Samples -Ten (10) Bougainvillea plants were purchased from Manila Seedling Foundation, Inc. The initial lead concentration of the plant and its soil were determined 
using Flameless Atomic Absorption Spectroscopy (FAAS). Plant samples were randomly assigned to two groups. The first group, labeled as the polluted group, was planted along the vacant area in the College of Pharmacy along Pedro Gil Street. The second group, labeled as the unpolluted group, was planted in a park in Las Piñas.

Soil Samples -soil samples from the two groups were collected. The soil lead concentrations were determined using Flameless Atomic Absorption Spectroscopy (FAAS).

Chemicals/Reagents -Nitric acid, Distilled Water

Instruments - Flameless Atomic Absorption Spectrophotometer (AA-6300, Shimadzu, France), FAAS controlled by a personal computer using WizAArd software

\section{B. Plant Harvesting and Heavy Metal Analysis}

Harvest of the plant samples were done at three time periods (3months, 6months, 9 months). For each harvest period, $1 \mathrm{~g}$ of mature leaves from each of the five bougainvillea plants planted in the selected sites (Manila and Las Pinas) was collected. Per group, the leaves were oven dried at $80^{\circ} \mathrm{C}$ for 24 hours. The samples were crushed into fine powder and sieve through $1.5 \mathrm{~mm}$ sieve [1]. To $1.0 \mathrm{~g}$ of the samples per each group, $10 \mathrm{~mL}$ of mixed solution of nitric and hydrochloric acid $\left(4 \mathrm{HNO}_{3}: 1 \mathrm{HCl}\right)$ was used to macerate the sample for seven days in closed polyethylene containers [1]. The samples were digested for 2 hours in $200^{\circ} \mathrm{C}$, until wet salts were obtained. Samples were then diluted to $50 \mathrm{~mL}$ with distilled water and analyzed by FAAS [1]. For the soil samples, $2.0 \mathrm{~g}$ soil were weighed per group then $4 \mathrm{~mL}$ of aqua regia $\left(\mathrm{HCl} / \mathrm{HNO}_{3}, 3: 1\right)$ was added. The samples were digested in a hot plate for three hours. The digest were filtered and made up to $20 \mathrm{~mL}$ with deionized water, transferred in polyethylene containers and stored at $4^{\circ} \mathrm{C}$ until analysis [1]. The leaves were macerated overnight for pre-digestion. The samples were then heated using a water bath maintained at $80-100^{\circ} \mathrm{C}$ for 5 hours, cooled, filtered and filled with distilled water to volume in a $50 \mathrm{~mL}$ volumetric flask [1]. The samples were transferred and stored in PET bottles prior to FAAS[1].

\section{1) Flameless atomic absorption spectroscopy}

The lead content of the samples was analyzed using flameless atomic absorption spectrophotometer (AA-6300, Shimadzu, France) controlled by a personal computer using WizAArd software. Measurements were carried out at 217.0 $\mathrm{nm}$ with $0.7 \mathrm{~nm}$ low slit and $5 \mathrm{~mA}$ electric current [5]. Prior to analysis, the spectrophotometer was calibrated with standard lead solutions $(0.05,0.1,0.50,1.00$, and $5.00 \mathrm{ppm}$ for the plant samples) using distilled water as blank. The standard solutions and distilled water were provided by the Chemistry Instrumentation Laboratory of the De La Salle University, Taft Avenue, Manila. Lead concentration levels were expressed in ppm unit.

\section{Analysis of Data}

Data were evaluated using the Data Analysis program of Microsoft Excel@. Student's two-way t-test: two samples assuming unequal variance was used to compare the lead concentration in the leaves of the two groups. Anova single factor was used to determine if there is a significant difference in the amount of lead accumulated in different time periods.

\section{RESUlTS AND DISCUSSION}

Table I shows that the total lead concentration (ppm) in soil samples is higher in Las Piñas than in Manila.

TABLE I: LEAD CONCENTRATION (PPM) IN SOIL SAMPLES IN MANILA AND

\begin{tabular}{l|l|l}
\multicolumn{3}{c}{ LAS PI NAS } \\
\hline & Manila & Las Piñas \\
\hline Lead in soil & 0.042467 & 0.51333 \\
\hline
\end{tabular}

\section{A. Heavy Metals in Plants in Manila}

Result of lead concentration present in bougainvillea plant in Manila is shown on Table II.

TABLE II: AMOUNT OF LEAD IN PLANT IN THE POLLUTED GROUP AT DIFFERENT TIME PERIODS

\begin{tabular}{l|l|l|l|l}
\hline $\begin{array}{l}\text { Polluted } \\
\text { environment }\end{array}$ & $\begin{array}{l}\text { Baseline } \\
\text { lead } \\
\text { content } \\
(\mathrm{ppm})\end{array}$ & $\begin{array}{l}3^{\text {rd }} \text { month } \\
\text { Lead content } \\
(\mathrm{ppm})\end{array}$ & $\begin{array}{l}6^{\text {th }} \text { month } \\
\text { Lead content } \\
(\mathrm{ppm})\end{array}$ & $\begin{array}{l}9^{\text {th }} \text { month } \\
\text { Lead } \\
\text { content } \\
(\mathrm{ppm})\end{array}$ \\
\hline P1 & 0.0049 & 0.2873 & $\begin{array}{l}\text { Not } \\
\text { detectable }\end{array}$ & $\begin{array}{l}\text { Not } \\
\text { detectable }\end{array}$ \\
\hline P2 & 0.0501 & $\begin{array}{l}\text { Not } \\
\text { detectable }\end{array}$ & 0.0011 & 0.035 \\
\hline P3 & 0.0689 & 0.0463 & 0.0162 & $\begin{array}{l}\text { Not } \\
\text { detectable }\end{array}$ \\
\hline P4 & 0.099 & $\begin{array}{l}\text { Not } \\
\text { detectable }\end{array}$ & $\begin{array}{l}\text { Not } \\
\text { detectable }\end{array}$ & 0.0237 \\
\hline P5 & 0.0802 & 0.0539 & 0.0011 & 0.02 \\
\hline Mean & 0.3031 & 0.3875 & 0.0061 & 0.0787 \\
\hline
\end{tabular}

It shows that bougainvillea plants planted in Manila varies in the amount of lead absorbed at a particular time period despite their similarity in terms of location, age and species. Fig. 1 shows that the mean concentration of lead in the bougainvillea plants was highest during the third month, October 2011, and lowest during the sixth month, January 2012. Such can be explained by the weather condition within which the samples were collected. The prevalence of rain was higher during the sixth month. The lead that might have been impringe in the leaves of the plants might have been wash away resulting to lower lead concentration detected during the sixth month. Aside from the mechanical removal of the lead in the leaves the lead deposited in soil can be washed off through mechanical removal such as soil erosion. Lead can also form complex to the components of the soil inhibiting the plants ability to absorbed lead from the soil.

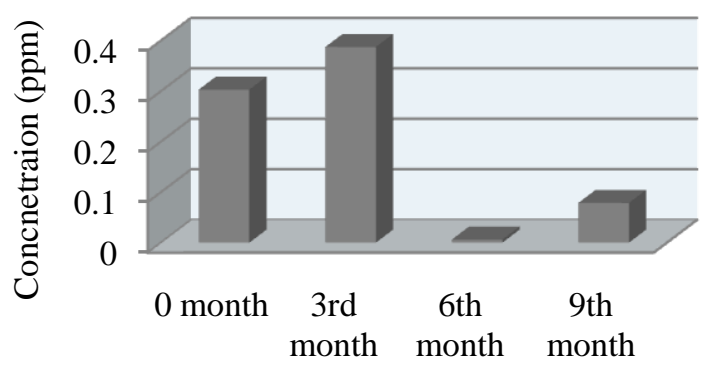

Time Period

Fig. 1. Mean lead concentration (ppm) uptake of Bougainvillea in Manila.

\section{B. Heavy Metals in Plants in Las Piñas}

Result of lead content present in bougainvillea plant in Las Piñas is shown on Table III. 
TABLE III: AMOUNT OF LEAD IN PLANTS IN THE UNPOLLUTED GROUP AT DIFFERENT TIME INTERVALS

\begin{tabular}{l|l|l|l|l}
\hline $\begin{array}{l}\text { Unpolluted } \\
\text { environment }\end{array}$ & $\begin{array}{l}\text { Baseline } \\
\text { lead content } \\
(\mathrm{ppm})\end{array}$ & $\begin{array}{l}3^{\text {rd }} \text { month } \\
\text { lead content } \\
(\mathrm{ppm})\end{array}$ & $\begin{array}{l}6^{\text {th }} \text { month } \\
\text { lead content } \\
(\mathrm{ppm})\end{array}$ & $\begin{array}{l}9^{\text {th }} \\
\text { month } \\
\text { lead } \\
\text { content } \\
(\mathrm{ppm})\end{array}$ \\
\hline P1 & 0.0501 & 0.035 & 0.0501 & 0.0124 \\
\hline P2 & 0.0463 & 0.0313 & 0.0501 & 0.0689 \\
\hline P3 & 0.0764 & 0.0727 & $\begin{array}{l}\text { Not } \\
\text { detectable }\end{array}$ & 0.0162 \\
\hline P4 & 0.084 & 0.0162 & 0.0802 & 0.0915 \\
\hline P5 & 0.0915 & 0.084 & 0.0539 & 0.0313 \\
\hline mean & 0.0696 & 0.04784 & 0.05858 & 0.04406 \\
\hline
\end{tabular}

It shows that individual bougainvillea plants planted in Las Piñas varies in the amount of lead absorbed at a particular time period despite their similarity in terms of location, age and species. Fig. 2 shows that the mean concentration of lead in the bougainvillea plants was highest during the sixth month and lowest during the ninth month. The results can be explained by the variations in the weather condition within which the samples were collected. The prevalence of rain in Las Piñas was higher during the ninth month.

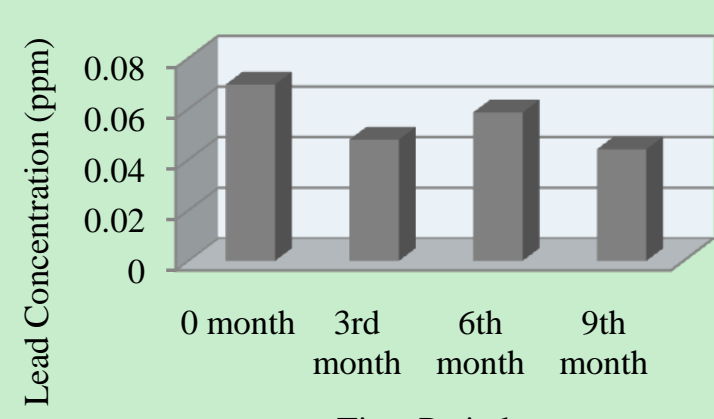

Time Period

Fig. 2. Mean Lead Concentration (ppm) uptake of Bougainvillea in Las Piñas.

Overall, comparing the amount of lead detected in the two cities, the bougainvillea plants in Las Piñas area contain greater amount of lead than the bougainvillea plants in Manila.

The result of $\mathrm{t}$-Test presented in Table IV shows that there is no sufficient evidence to conclude that the lead content of the plants in Manila differs significantly from the lead content of the plants in Las Piñas.

TABLE IV: T-TEST RESUlT OF LEAD CONTENT IN MANILA AND LAS PINAS

\begin{tabular}{l|l|l}
\hline & Manila & Las Piñas \\
\hline Mean & 0.056264286 & 0.054847368 \\
\hline SD & 0.005325895 & 0.000691306 \\
\hline Observations & 0.072978728 & 0.026292698 \\
\hline Hypothesized Mean Difference & 0 & 19 \\
\hline Df & 14 & \\
\hline t-Stat & 16 & \\
\hline P $(\mathrm{T}<=t)$ two tail & 0.069402919 & \\
\hline T Critical two-tail & 0.94552891 & Not significant \\
\hline
\end{tabular}

The result of ANOVA presented in Table $\mathrm{V}$ shows that there is no sufficient evidence to conclude that lead content of the bougainvillea leaves increases or decreases significantly over time. Moreover the result is further supported by the variations and absence of patterns in the mean lead levels detected in the soil and the plants at different time periods.
TABLE V: ANOVA SINGLE FACTOR OF LEAD CONCENTRATION IN DIFFERENT TIME PERIODS

\begin{tabular}{l|l|l|l|l|l|l}
\hline $\begin{array}{l}\text { Source of } \\
\text { variation }\end{array}$ & SS & df & MS & F & P-value & F crit \\
\hline $\begin{array}{l}\text { Between } \\
\text { groups }\end{array}$ & 0.01036 & 3 & 0.00346 & 1.4045 & 0.26143 & 2.9340 \\
\hline $\begin{array}{l}\text { Within } \\
\text { groups }\end{array}$ & 0.07133 & 29 & 0.00246 & & & \\
\hline & & & & & & \\
\hline Total & 0.08169 & 32 & & & & \\
\hline
\end{tabular}

The result of accumulation and absorption of the bougainvillea plant in the study can be accounted to external factors that might have affected the plants' capacity to uptake lead from the environment. The presence of lead in plants is essentially due to the absorption of atmospheric lead directly from their leaves or from their bark [6]. However plants have different methods to entrapped or removed heavy metal contaminants in the soil. There were already variations in their initial lead content prior to the start of the experiment that may cause the differences in the lead concentration of plants in different time period. Another factor which might affect the lead uptake is the concentrations of heavy metals in soil [6]. Lead in soil can be transported to other places during heavy rainfall, and soil erosion. During the $3^{\text {rd }}$ ( October 2011) and $6^{\text {th }}$ month (January 2012), heavy rainfall was experienced in the Taft area as compared to Las Piñas thus the air borne lead adsorbed by the plant through their leaves might have been washed off during the collection period. Moreover Taft area was often flooded as compared to Las Piñas and thus the lead that possibly present in soil may be washed off resulting to lower lead level retain in the soil.

\section{CONCLUSIONS AND RECOMMENDATIONS}

Lead uptake of bougainvillea plant species planted in Manila and Las Piñas was studied. Results show that bougainvillea lead uptake may vary depending of different environmental factors such as concentration of lead in soil and climatic condition, degree of heavy metal pollution, and complex of lead form in other soil component. The study recommend the used of simulated soil and controlled environment to minimized the effect of extraneous variables that might affect the absorption and adsorption of lead in bougainvillea plant to established the plants ability to absorbed lead before testing it to the actual environment.

\section{ACKNOWLEDGMENT}

The authors thank the University of the Philippines Manila, College of Pharmacy for their generous support in making this paper possible. They would also like to thank the following contributors who have shared their time and expertise in the attainment of the objectives of this study, namely: (1) Aninon, A.D., (2) de Luna, A., (3) Bacala, C., (4) Cosme, K., (5) Rodriguez, C., (6) Ong, A., (7) Real, M., (8) Paguirigan, J., and (9) Alvarado, J.

\section{REFERENCES}

[1] J. Shehu, A. Mullaj, A. Maci, and A. Shehu. (2010). Using high plant species as idicators for the accumulation of lead from polluted air. [Online]. Available: http://www.balwois.com/balwois/administration/full_paper/ffp-1645. pdf. 
[2] Yan-Ju and D. Hui, "Variation in air pollution tolerance index of plants near a steel factory. Implications for landscape-plant species selection for industrial areas," Environ. Dev., vol. 1, no. 4, pp. 24-30, January, 2008.

[3] H.-Y. Lai, S.-W. Su, H.-Y. Guo, and Z.-S. Chen, "Heavy Metals Contaminated Soils and Phytoremediation Strategies in Taiwan," in Soil Contamination, MSc Simone Pascucci (Ed.), chapter 6, September 2011.

[4] F. Fajardo, Economics, 3rd ed., Philippines: Rex Bookstore, Inc., pp. 357. May 1995.

[5] M. C. Jung. (2008). Heavy Metal Concentrations in Soils and Factors Affecting Metal Uptake by Plant in the Vicinity of a Korean $\mathrm{Cu}-\mathrm{W}$ Mine. [Online]. Available: http://www.mdpi.org/sensor

[6] R. Freydier and J. Viers. (2003). Isotopic study of lead transfer at the interface soil plants atmosphere. Geophysical research letter, [Online]. 30(1227). http://www.agu.org/pubs/crossref/2003/2002GL016145.shtml

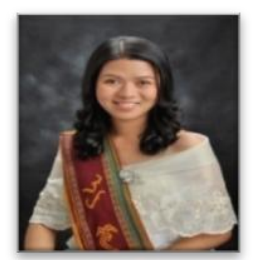

Karen Ann Marie M. Dela Cruz is currently studying B.S. Pharmacy at the University of the Philippines Manila. She is currently the president of UP Salikasan a research based organization in the UP College of Pharmacy that conduct researches relevant to the environment and public health safety. She was a co-author of three papers published internationally. In line with her interest of studying the current environmental conditions in the Philippines most of her papers was focused on the assessment of the presence of pollutants in the environment particularly on heavy metals. Her first paper entitled "Lead Uptake of Peppermint (Mentha piperita) Grown on Simulated Polluted Soil" was presented and published in the 2nd International Chemical and Environmental Engineering Conference (ICEEC 2011) held last December 21-23, 2011 at Kuala Lumpur Malaysia. Her two other research papers were recently published and presented in the 2nd International Conference on Environment and BioScience (ICEBS 2012) held last September 28-29, 2012 at Phnom Penh, Cambodia entitled "A Quantitative Analysis on Cadmium and Chromium Contamination in Powdered Children's Milk Available in Metro Manila, Philippines" and "Determination of Lead in Soil and Plants and Risk Assessment of its effects among preschool Children in Daycare Center in Manila, Philippines".

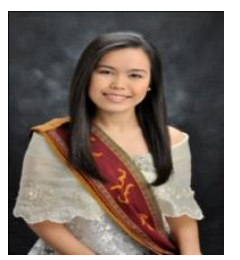

Sandra Dawn G. Burgos is a B.S. Industrial Pharmacy student at the University of the Philippines, Manila. She is currently the vice president of UP Salikasan, a research-oriented organization in UP College of Pharmacy that deals with scientific approaches in gaining knowledge about the environment and applying this learning in taking care of mother earth. Two of her research papers were published internationally and she was able to present one of these in the 2nd International Conference on Environment and BioScience (ICEBS 2012) held last September 28-29, 2012 at Phnom Penh, Cambodia. The title of the paper she presented is "A Quantitative Analysis on Cadmium and Chromium Contamination in Powdered Children's Milk Avaliable in Metro Manila, Philippines" and the other paper that is published is entitled "Determination of Lead in Soil and Plants and Risk Assessment of its effects among preschool Children in Daycare Center in Manila, Philippines". Recently, she had another recognized scientific paper entitled "Determination of the Antimicrobial Activity of Blumea balsamifera (Linne.) De Candolle (Family Asteraceae)" which will be presented at the 17th Natural Products Society of the Philippines Convention at Bacolod, Philippines.

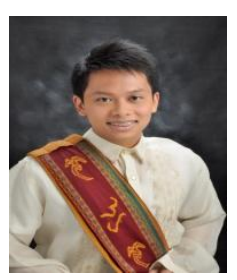

Mac Ardy J. Gloria is a $5^{\text {th }}$ year B.S. Industrial Pharmacy student at the University of the Philippines Manila, College of Pharmacy. Presently, he is the secretary-treasurer of UP Salikasan, which is the only research-oriented organization in the aforementioned College. Two of his research studies have been published nationally, namely: (1) "Spectrophotometric Determination of Nitrites in Drinking Water based on Catalytic Reaction of Methylene Blue and Potassium Bromate", and (2) "Determination of the Antimicrobial Activity of Blumea balsamifera (Linne.) De Candolle (Family Asteraceae)". The former was presented at the $27^{\text {th }}$ Philippine Chemistry Congress: A Joint Conference at Mandaluyong Philippines; while the latter was presented at the $17^{\text {th }}$ Natural Products Society of the Philippines Convention at Bacolod, Philippines.

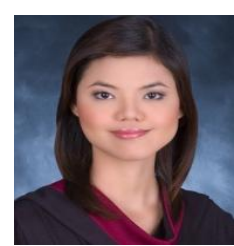

Khristie Michelle D. Ventura is a member of the Saliksikan para sa Kalikasan organization. Ms. Ventura is a Filipino citizen and is 23 years of age. Ms. Ventura is a BS Industrial Pharmacy student of the University of the Philippines.

She has undergone internships in the community, hospital and industrial pharmacy settings. She is also one of the authors of a research paper entitled Quantitative Determination of Formaldehyde in Air in Selected Laboratories in the University of the Philippines Manila-Philippine General Hospital presented in the 2012 2nd International Conference on Environmental and Agriculture Engineering of the International Proceedings of Chemical, Biological and Environmental Engineering held at Jeju, Korea. The said paper was published by the IACSIT Press and is available online through Google.

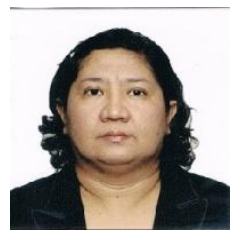

Judilyn Solidum is a senior member of the Asia Pacific Chemical, Biological and Environmental Engineering Society. She was born in Makati, Philippines on October 14, 1968. She graduated from the University of the Philippines, College of Pharmacy with the degree of Bachelor in 1989. She received her MS Diploma for Pharmacology in 1998 at the University of the Philippines, Manila in 1998. She obtained her PhD degree for Environmental Science at The University of the Philippines, Los Banos, School of Environmental Science and Management in 2006. She has since been engaged in researches realted to drug discovery and mechanisms of drug action, as well as eco-toxicology with emphasis on contaminant monitoring and its removal.

She has been working as Faculty at the University of the Philippines, Manila, College of Pharmacy since 1990. She is a current Associate Editor to the Research Journal of the National Research Council of the Philippines. She had published several research articles in peer reviewed journals like Journal of Environmental Science and Management, Annals of Engineering, International Journal of Chemical and Environmental Engineering, International Journal of Bioscience, Biochemistry and Bioinformatics. She also contributed to peer reviewed proceedings of the International Proceedings of Chemical, Biological and Environmental Engineering, International Proceedings of International Conference on Bioinformatics and Biomedical Engineering-Environmental Pollution and Public Health among others. 